\title{
Applications of Optimisation in Serious Games Design: An Integrated Framework
}

\author{
Ayman Tobail \\ Technological University Dublin, aymen_2000@yahoo.com \\ Amr Arisha \\ Technological University Dublin, amr.arisha@tudublin.ie
}

Follow this and additional works at: https://arrow.tudublin.ie/buschmarcon

Part of the Technology and Innovation Commons

\section{Recommended Citation}

Tobail, A. \& Arisha, A., (2017). Applications of Optimisation in Serious Games Design: An Integrated Framework. In Proceedings of International Technology, Education and Development Conference, Valencia, Spain, 2017

This Conference Paper is brought to you for free and open access by the School of Marketing at ARROW@TU Dublin. It has been accepted for inclusion in Conference papers by an authorized administrator of ARROW@TU Dublin. For more information, please contact arrow.admin@tudublin.ie, aisling.coyne@tudublin.ie, gerard.connolly@tudublin.ie.

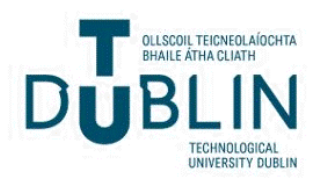




\title{
APPLICATIONS OF OPTIMISATION IN SERIOUS GAMES DESIGN: AN INTEGRATED FRAMEWORK
}

\author{
Ayman Tobail \\ Amr Arisha \\ Dublin Institute of Technology (DIT) (Ireland)
}

\begin{abstract}
It is becoming increasingly difficult to adapt new teaching methods especially when addressing complex subjects of management such as operations management (OM) and supply chain management (SCM). Simulation-based serious gaming is one of the promising new approaches that leverage the learning ability for the current students - known as Digital era generation. Literature review shows few to no attempts to offer formal guidelines for the development process of serious games that are designed for education purposes. Combining and balancing objectives of learning, entertaining, keeping an active instructor role, while collecting real-time learning efficiency indicators is the main purpose of this study. The study proposes a comprehensive framework to underpin the development of simulation-based serious game - AUSUM (AUtomobile SUpply chain Management) that can be used to support learning supply chain concepts such as supplier selection, production planning, order fulfilment, inventory management and more. Results demonstrate a very high satisfaction level from the learners on the usability and learning technique. Integrating optimisation with simulation has also enabled the game to offer different learning modes with different configurations in order to accommodate the level of learners and style of learning.
\end{abstract}

Keywords: Serious games, Simulation games, Supply chain management.

\section{INTRODUCTION}

Successful supply chain operations depend essentially on the effective integration between business processes and network members so as to that achieve synchronization between all processes to realise overall system objectives. This synchronisation is exposed to dynamism, uncertainty, largescale processes and flows and multi-functional challenges which together lead to high supply chain complexity, the degree of which relates to the number and diversity of the supply chain elements. Adopting a suitable business model in a highly complex supply chain is a challenging process, due to the boundless data, performance trade-offs, constraints and decision variables that must be taken into account.

Lack of understanding of supply chain performance variables and drivers and poorly designed and ineffective management strategies make it difficult to identify the real causes of supply chain complexity. Lectures and traditional ways of learning can provide students with theoretical knowledge, but is likely to fail to develop the practical skills they need for their future careers [1], so that students struggle to appreciate the links between supply chain concepts and their application. To overcome this situation, learning organizations need to create and employ novel approaches to teaching and learning. The current generation's learning style differs from those of previous generations in being much more interactive, visual and problem-based [2]. Universities are increasingly embracing simulation as an important method of improving students' learning abilities in operations managementrelated courses. Simulation tools' strengths follow from their employing time dimensions and modelling the real world using building blocks, systems' variables and scenarios' application. On the other side, their weaknesses follow from the fact that analysis characteristics can overshadow current applications of discrete event simulations, the lack of pedagogical perspectives and their inability to include interactive player roles in the system. The trend toward accepting games in education started slowly [3], but has increased in the recent decade due to their learning characteristics - creating a virtual world for each player to practice at their own individual rate, and providing the freedom to examine various scenarios and make errors without painful failure [4].

Research and studies have covered several aspects of learning in games such as learners' ability to combine information from different areas to come up with solutions or make decisions and examine 
their impacts on game flows [5],. Communication between students during playing sessions improves their social skills by encouraging them to contact each other to discuss, negotiate and decide their playing strategies collaboratively, dealing with conflict solutions and planning next steps in the game journey [6]. Teachers have to also ensure that they incorporate fair and robust assessment techniques when gaming is used in learning [7]. This study develops a novel framework for simulation-based serious game integrating optimisation techniques to leverage the learning ability for students in complex fields such as supply chain management. Various decision-making points were handled in different scenarios applied and controlled by the instructor to preserve the instructor role in the classroom.

\section{SIMULATION-BASED SERIOUS GAMES}

Over the past decade, simulation-based serious games have increasingly been adopted as learning and training tool. It is not surprisingly that serious games are being employed widely in such learning environments as classroom education, healthcare and hospitals training, government and military departments. The rapid growth of the adoption of serious games in training and education areas relates to three main factors highlighted by [8]. The first factor focuses on dealing with serious games as a new trend in teaching and learning field that implements three major changes; replacing teachercantered by learner-cantered approaches; transforming listen-based instruction models of learning to doing and interaction-based models; and replacing a learning concept based only on memory with one that depends on the capabilities of finding and using information. The second factor concerns the development of interactive technologies that engaged students actively in problem solving, while the third is the power of serious games to grab the attention of students to the curriculum and bring them on board.

Research studies have reported several aspects of learning in games such as the learners' ability to combine information from different areas and develop a solution or make a decision and examine its impact on the game flow [9]. There is a wide scope for the use of simulation as an aid to these learning techniques. Successful adoption for simulation is highlighted in medical [10], engineering [11] and science schools. Individual attempts have adopted simulation games in subjects such as economics [12], health [13], and engineering [14]. Business modules, including supply chain management, are one area where successful implementation can be most effectively achieved.

Optimisation techniques are integrated into simulation systems to enhance their capacity to find optimum solutions for complex problems, especially when the objectives involved are conflicting and the problems have enormous numbers of variables. In production and planning, [15] developed a framework using simulation-based optimisation to detect the production parameters. A hybrid simulation optimisation approach has been shown to be effective when applied to the design and control of supply chain network that involve various controlling factors, such as demand and supply uncertainty and performance indicators that represent cost and responsiveness [16]. In supply chain management, stock level problems were targeted by [17] through a simulation-based optimisation model in order to find the optimum stock level. In flow shop scheduling [18] a hybrid simulation optimisation approach is used to overcome the complex and stochastic nature of the problem. In production and planning, [15] developed a framework using simulation-based optimisation to detect the production parameters. That makes tools based on the integration between simulation and optimisation promising for achieving valuable solutions to complex problems. However, the fundamental problem was, and remains, that no formal guidelines and steps exist on how to integrate an optimiser in a serious game framework, and how to get the benefits of that integration. van der Zee [19] were the first to propose a formal conceptual model of simulation-based serious games to integrate discrete event simulation within gaming environments. Discrete event simulation was successfully used in supporting serious games [20]-[22]. There have been few attempts in various games to build roles similar to the optimisation role to provide players with suitable solution for the current situations they faced, but these trials lacked formal frameworks, and did not focus on measuring the optimizer's effect on leveraging knowledge, but instead, it focused on measuring the effect of the whole game on achieving learning [20]. To fill the gap in the literature of integrating optimisation into simulation-based serious games, this paper develops an integrated serious game. 


\section{AUSUM FRAMEWORK DESIGN AND CLASSROOM INTEGRATION}

The frameworks of learning games must integrate both their educational and entertainment characteristics and dimensions [23]. The educational component defines how the game is employed as a learning tool, specifying the learning objectives and how it is used in the classroom [24]. The entertainment component determines how it involves engaging and fun elements [25]: both components together build a challenging, engaging experience for students to fulfil certain learning goals set by pedagogical objectives. In addition to these two components, the proposed framework integrates a third component as illustrated in the Fig. 1 framework structure, which also represents the game's practices for supervising and guiding students. The first formal simulation-based serious game framework proposed by [19] focused only on the integration between simulation and games, but there was no consideration of students' supervisory or guideline dimension.

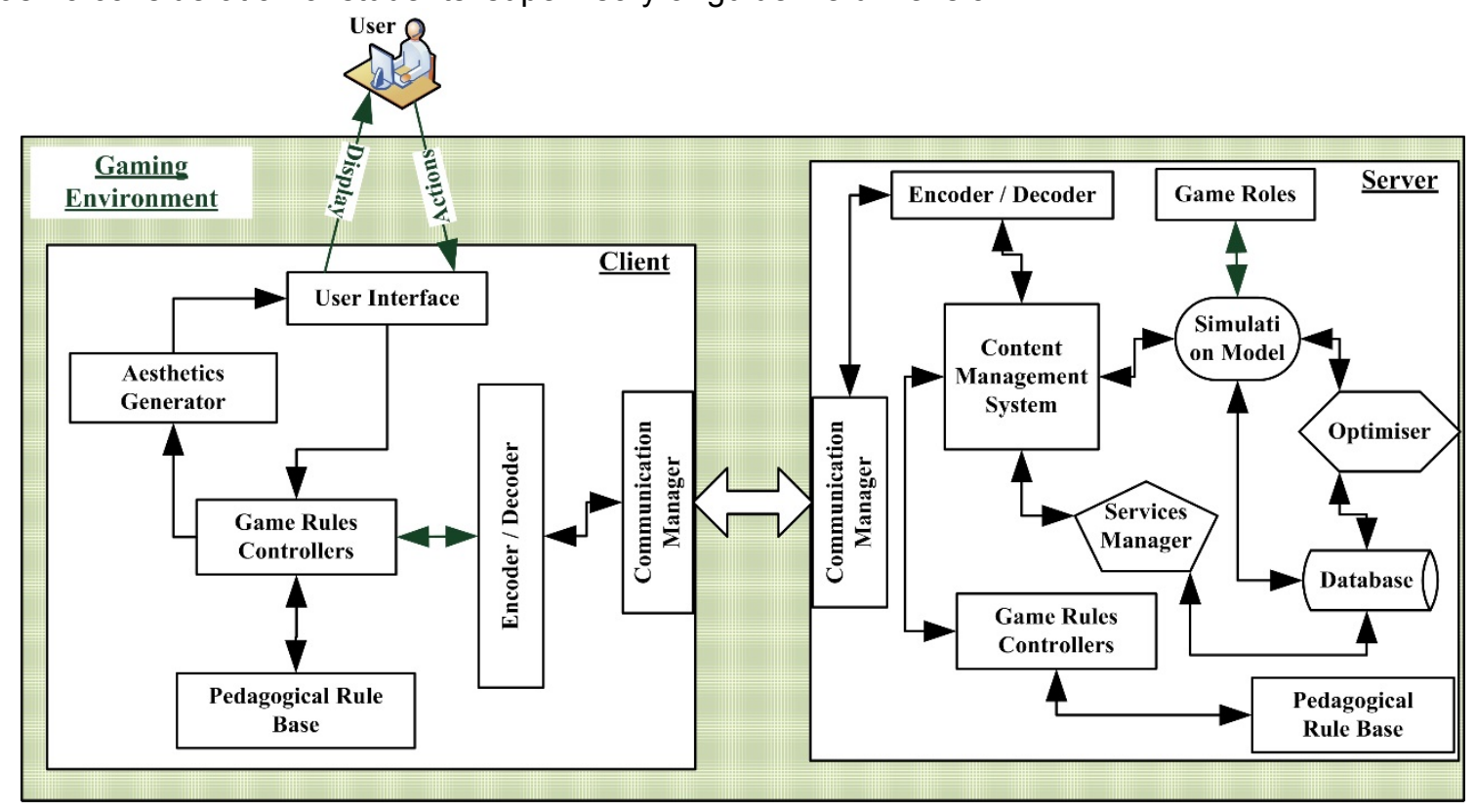

Fig. 1. The AUSUM client-server framework structure

Pedagogical, entertaining, and optimisation components were taken into consideration in the design process of the framework. The AUSUM (Automobile Supply Chain Management) game was designed to simulate an automobile supply chain network. Students can choose to play any of three roles, as manufacturer, distribution centre, or retailer, and enacts that role via a comprehensive graphical user interface, which includes a playground section, control panel, monitor and statistical charts section, updates window, and ranks, performance and pedigree indicators. The 'playground' section displays the role's basic components and animation. The control panel receives the player's actions and transfers them to the client software. Graphical statistical indicators and charts give the player feedback on their performance, so helping them to improve it.

Players/learners proceed to play (i.e., manage) their chosen roles by applying orders to their upstream suppliers to receive goods in order to replenishment the warehouse. Players receive sales orders from their downstream partners, which they must fulfil from the warehouse stock. Players have to manage their inventory so as to minimize costs and maximize their profits. Manufacturer players assemble cars using materials from different suppliers, such as metal sheets, tires, engines, etc.. Retailers receive orders from customers at a rate that is pre-set by the game's administrator. Both administrator and instructor roles could be handled by the instructor. For all players, deciding the order quantity and time to make the orders for warehouse replenishment is considered as challenging decision point. In playing their management roles, players must decide which other(s) of the available players to link with as partner(s). The automobile industry was chosen for our application field for two reasons; (1) supply chain activities represents $70 \%$ of the industry's activities, (2) undergraduate students are interested in different car models and their specs.

Essentially, AUSUM was developed to provide a flexible and configurable teaching aid in a gaming environment to help instructors in major supply chain management courses; to help students develop 
knowledge and practical skills by examining various supply chain scenarios that would enhance collaboration and interaction between players; and to deliver a test-bed environment for supply chain management theories while helping researchers evaluate students' decision making behaviours and analyse the results to identify teaching references, or for other research purposes. Based on comprehensive conceptual models, each role was designed and implemented as shown in Fig. 3, which describes the game story, rules, and available operations for each player. The instructor can adjust the logistics controlling the game's parameters to generate different rates of accidents and delays in the shipping process, which introduce levels of uncertainty into the supply chain network that require players to examine whether they need to insure against uncertainty.

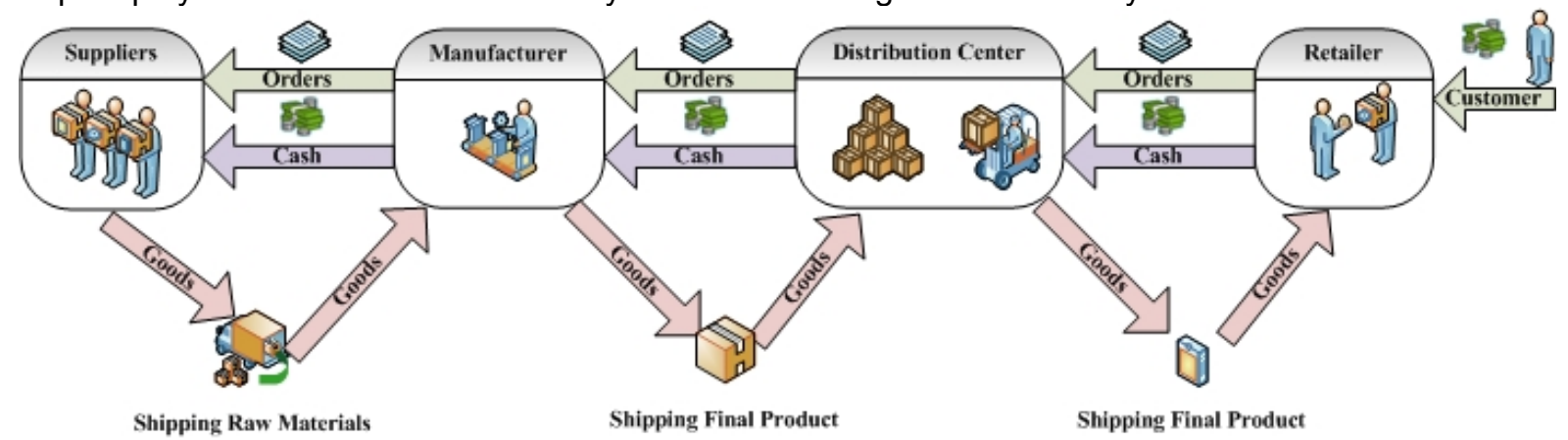

Fig. 3. Supply chain flows

\section{AUSUM ARCHITECTURE}

The AUSUM game is designed on a client-server model where the server hosts scripts and the database, and the client runs the player application: they communicate over the Internet using HyperText Transfer Protocol (HTTP). Encoder/decoder modules are added to both sides to handle interactions between client actions and server responses via the HTTP protocol. Fig. 1 shows the AUSUM architecture (Simulation-Optimisation Integration). The Communication Manager listens to the messages over the client/server communication channels, each message consisting of various fields to identify the client identity, the required operation and its parameters. This system guarantees the game's security policy and handles users' access permissions according to their user type - student, instructor, or administrator through the content management system. The comprehensive relational database system was designed according to an ER (Entity-Relationship) to handle users' information, game rules, simulation model variables, historical data, and meta-data and reports. A discrete event simulation model was developed on the server to imitate goods, information and cash flows between the SC entities represented in players' client applications. Actions taken by players on the client side are transferred to the server side, thus modifying the simulation model variables' settings. The impacts on the simulation model influenced by the variables' settings are sent back to the client side application, where they are represented via its friendly graphical interface. The optimizer module comprises main three components; the interface, the mode controller, and the optimizer core. The optimizer input parameters are received from the simulation model and database via the optimizer interface where they are validated and prepared for the optimizer core, which uses an optimisation algorithm to receive inputs and search for solutions to current problems in the solution space, taking the defined constraints into consideration. The optimum solution for the current simulation problem is stored in the database to be retrieved via the player's or instructor client applications. The instructor can apply various optimiser operational modes to set up its response behaviour. In passive mode, the optimizer generates optimum solutions to be saved in the database to allow the instructor to trace players' performance, but the optimizer is hidden in the player's client application (passive). In the active mode, players are given historical charts, which compare between their decisions and the optimizer decisions.

\section{AUSUM PLAYING AND INTERFACES}

At the start of each experimental session, the administrator/instructor configures the game via an efficient, user-friendly interface (Fig. 5) for the unlimited number of players, and sets the demand and supply patterns to fulfil the learning objective to be delivered to players/learners. Supplier delays and accident rates can be adjusted to be generated randomly to embed uncertainty into the whole network, which forces players to think about insure goods before shipping. At end of each experimental session, all results are saved so the instructor can review statistical reports. 


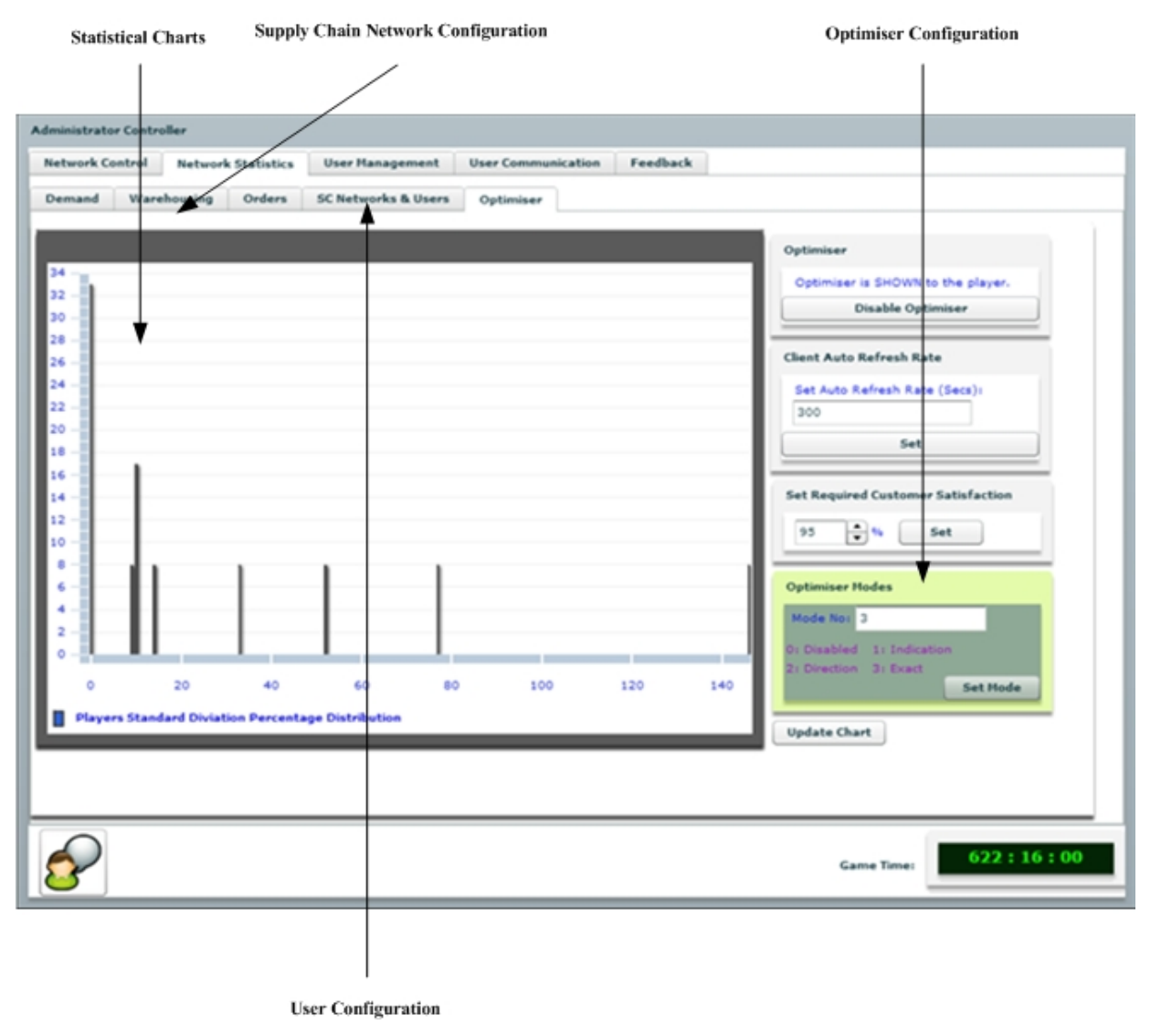

Fig. 5. The administrator's interface

The AUSUM game can be played in single or multi-player modes. For single players, the instructor allocates the students certain roles (manufacturer, distribution centre, or retailer) and controls the whole network and all parameters involved from their client application. In the multi-player mode, each player performs as a part of the whole supply chain network. Each player's PC has a user-friendly interface to facilitate controlling the various processes and follow the results and performance indicators (see Fig. 6). Its main component is a 'playground', which shows animations of goods and trucks etc., and visual indicators of player's actions and server responses, as well as special icons such as cars and personal characteristics to make it more attractive and engaging to the players. There is also a control panel with assigned buttons for managing functions, e.g. making orders, linking to partners, starting manufacturing cars, shipping, and applying maintenance efforts. Ranking, player's pedigree degree and score points windows update players as to their current rank among other players and pedigree degree status. Another button is assigned to show players' network connections with other upstream and downstream partners. An optimizer window showing a detailed chart comparing the player's and the optimizer's actions can opened from the control panel, and performance indicators and statistics are displayed in order statistics windows and warehouse monitors. The instructor interface was designed to provide the instructor with initializing, tracing and monitoring facilities, the ability to make real-time intervention, and receive results and reports about players' performances. After initializing the game, the instructors watch and trace players' performance and checks reports so they can intervene at any time to change game parameters as needed.

Information about each player including players' ranks, current playing levels, lead times, and penalties or rewards gained are provided by the server to be displayed in each player's window, and those of their partners, which helps players trying to make decision about choosing suitable network partners. Players send purchase orders to their upstream partners to receive goods within certain lead times (if the order is accepted): the same applies to sales orders (but with the stream in the opposite direction). Lead times, warehouse monitoring, and expected demand information are displayed; as they are crucial elements in helping players decide order quantities. An optional insurance facility is provided for each order to cope with uncertain accidents that could happen according to a rate 
configured by the instructor. Learners playing all game roles are shown previous decision points; partner selection, order quantity, insurance, warehouse replenishment, capacity while production planning is for manufacturer role only.

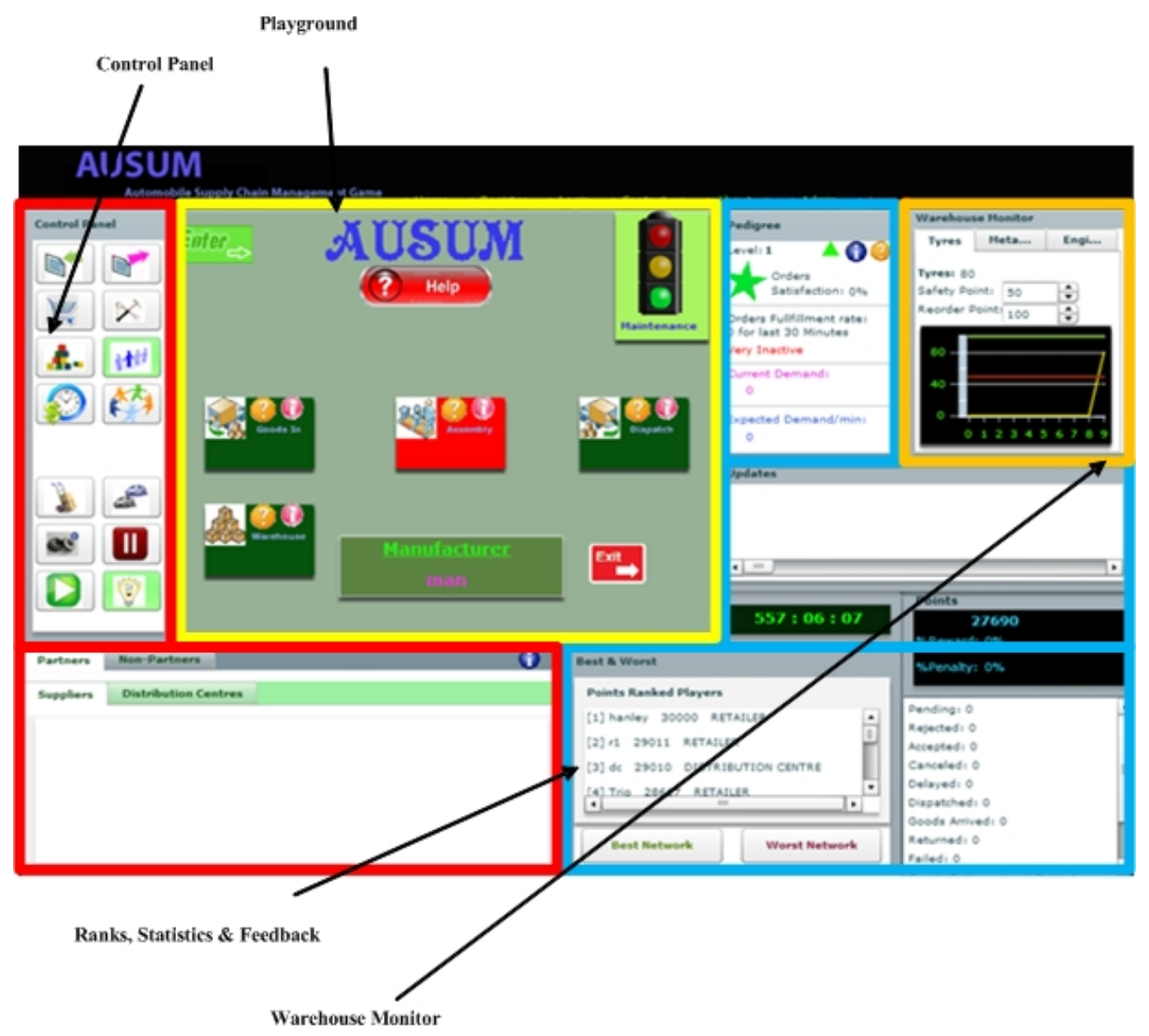

Fig. 6. The player's interface

\section{EXPERIMENTS}

The AUSUM game was tested in classroom settings to study its impact on students and analyse its success as a learning tool: this section presents the design and results of this experiment, whose primary goal was to evaluate the effectiveness of the proposed framework in achieving its pedagogical goals and its engaging and entertainment aspects, and to evaluate the influences of integrating the optimiser agent into serious games frameworks. This experiment was applied in the setting of a college of business for students attending supply chain management course. 142 students were recruited for this study: they were first given an introduction to the game, and then asked to play the game during a lecture session. The instructor controlled the game by setting its control variables and scenarios, and enabling various optimiser modes. Students were asked to form groups of 3-4 and instructed play one of the roles (manufacturer, distribution centre, or retailer). Comments and observations were collected during the playing session to reflect students' interest in the game, and an open discussion was held afterwards during which they were invited to comment on and evaluate the game. To assess the experiment's outcome, a five-point Likert scale ranging from "strongly disagree" to "strongly agree" was adopted in a questionnaire approach. This questionnaire is divided into three sections as seen in Table 1: in the first, a usability survey was employed to measure the game's usability and engagement: the second section concerned its pedagogical achievement, and the third evaluated the integration of the optimiser. 


\section{RESULTS AND DISCUSSION}

The results collected from the questionnaire showed a remarkable degree of acceptance of the game on the part of the students (see in Fig. 8). Their comments and discussions revealed they were interested in playing for a longer period and over more sessions. The usability survey results emphasized the efficiency of the game, which enabled students to progress through the game functions with minimum help from their supervisors. Students were very interested in the game features, to the degree that some students explained some options to others. Discussions about SC concepts between students were observed during the playing session, which highlighted both the game's advantages for improving both the social dimension and knowledge exchange. Some students were so motivated; they used pen and paper to make calculations to decide the order quantities.

Students' comments on the game session included:

- Animation was very helpful in illustrating the movements of elements through the whole supply chain network.

- Being mindful of the three areas (manufacturer, retailer, and supplier).

- Enjoyable way of learning

- Learned new supply chain concepts like ordering, lead-times, stock levels and replenishment.

- Gave good insights about the importance of simulation in SC and better understanding of supply chain network

- Best learning concepts were SC flows and replenishment

- Learned about the risks of holding too much stock, receiving and delivering orders, and lead times.

Data were collected about the game's teaching ability and the achievement of learning objectives see Fig. 8 (Learning Objectives and Teaching Aspects) - which shows that - in general - the students 'agreed' or 'strongly agreed' that the game succeeded, in that they achieved greater understanding and improved their skills during the game session. Descriptive analysis of the relevant section of the questionnaire was used to evaluate the optimiser feature: as Fig. 8 (Optimizer Integration) shows, the assessment of the value of integrating this feature is significantly skewed towards 'agree' and 'strongly agree' responses. Table 1 illustrates students' responses regarding usability of the game, learning objectives, teaching aspects, and optimizer integration. As shown in the table, most of the mean scores skew towards general agree and strongly agree with the game usability - see Fig. 8 (Usability), learning and teaching features and optimizer role. It also shows that they were interested to play the game for more sessions and they were satisfied with the level of communication and cooperation created by using the game. Meanwhile, they commented on the interface of the game that it needs to be more simplified and they needed an introductory session before playing the game.

\section{CONCLUSION AND FUTURE WORK}

The relationship between performance variables of supply chains is a challenge due to the complexity and the high level of uncertainties embedded in the system. This can put extra pressures on supply chain instructors and trainers to find a way to explain and teach implications of decisions. Simulation based games have a proven record of engaging students in exciting learning process. Students of the current generation enjoy access to technologies that classroom never witnessed before, hence advances in gaming has helped to create an appealing learning environment for them. This paper presents the validation of a new gaming framework that can be used as part of teaching complex concepts in business applications. This framework integrates the required components (i.e. Simulation model, optimiser, Interactive gaming interface and engine, Pedagogical knowledge-base???) to achieve both pedagogical and entertainment aspects in order to keep suitable level of student engagement and equally useful knowledge retention. Validation of this framework has attested to the design and implementation of a supply chain serious game (AUSUM) based on the proposed framework and its experimental application in a real classroom context. An evaluation of the experiment revealed that the facilities given to the instructor encouraged the use of the game as a teaching tool for a particular and relatively complex subject to a group of learners. Statistical analysis of the questionnaire results validated its effectiveness for teaching supply chain concepts. One of the game's motivational and engagement factors is its social component, where the collaboration between students required in many situations adds social dimension and dynamics to the game environment. 
Table 1: Questionnaire analysis.

\begin{tabular}{|c|c|c|}
\hline Question & Mean & Standard Deviation \\
\hline \multicolumn{3}{|l|}{ Usability of game: } \\
\hline I think that I would like to use this system frequently & 3.13 & 1.28 \\
\hline I thought the system was easy to use. & 3.07 & 1.03 \\
\hline I found the various functions in this system were well integrated. & 3.60 & 0.76 \\
\hline I would imagine that most people would learn to use this system very quickly. & 3.50 & 1.15 \\
\hline I felt very confident using the system. & 3.17 & 1.04 \\
\hline \multicolumn{3}{|l|}{ Learning objectives: } \\
\hline The game increased my interest and knowledge about supply chain management. & 3.63 & 0.91 \\
\hline I better communicate, cooperate and share knowledge with my group members via the game & 3.63 & 1.02 \\
\hline The game improved my decision-making and problem solving skills. & 3.60 & 0.92 \\
\hline The lessons learned from the game can be applied to the real-life situations & 3.77 & 1.02 \\
\hline The game helped me in understanding the concept of lead time & 3.77 & 0.92 \\
\hline The game helped me understand the concepts of supply chain network collaboration & 3.90 & 0.94 \\
\hline I think sharing information between players helped improving my decisions & 4.00 & 0.77 \\
\hline The game helped improve my strategies for inventory management & 3.70 & 1.00 \\
\hline I was able to calculate the order quantity easily using information provided by the game & 3.23 & 0.92 \\
\hline \multicolumn{3}{|l|}{ Teaching Aspects: } \\
\hline The game is a positive contribution to the curriculum. & 3.77 & 1.15 \\
\hline I prefer the simulation game approach to conventional teaching methods. & 3.97 & 1.14 \\
\hline I am interested in playing the game for more sessions. & 3.50 & 1.15 \\
\hline $\begin{array}{l}\text { The game motivated me to learn the rules of calculating the order quantity by clicking learn } \\
\text { about order quantity button. }\end{array}$ & 3.57 & 1.02 \\
\hline \multicolumn{3}{|l|}{ Optimizer Integration: } \\
\hline The optimiser was helpful to direct me to take better decisions. & 3.60 & 0.71 \\
\hline Optimiser enabled me to understand concepts like optimum order quantity & 3.57 & 0.88 \\
\hline $\begin{array}{l}\text { Checking my previous decisions and compare them with the optimiser decisions enhanced } \\
\text { my decisions }\end{array}$ & 3.63 & 0.84 \\
\hline
\end{tabular}




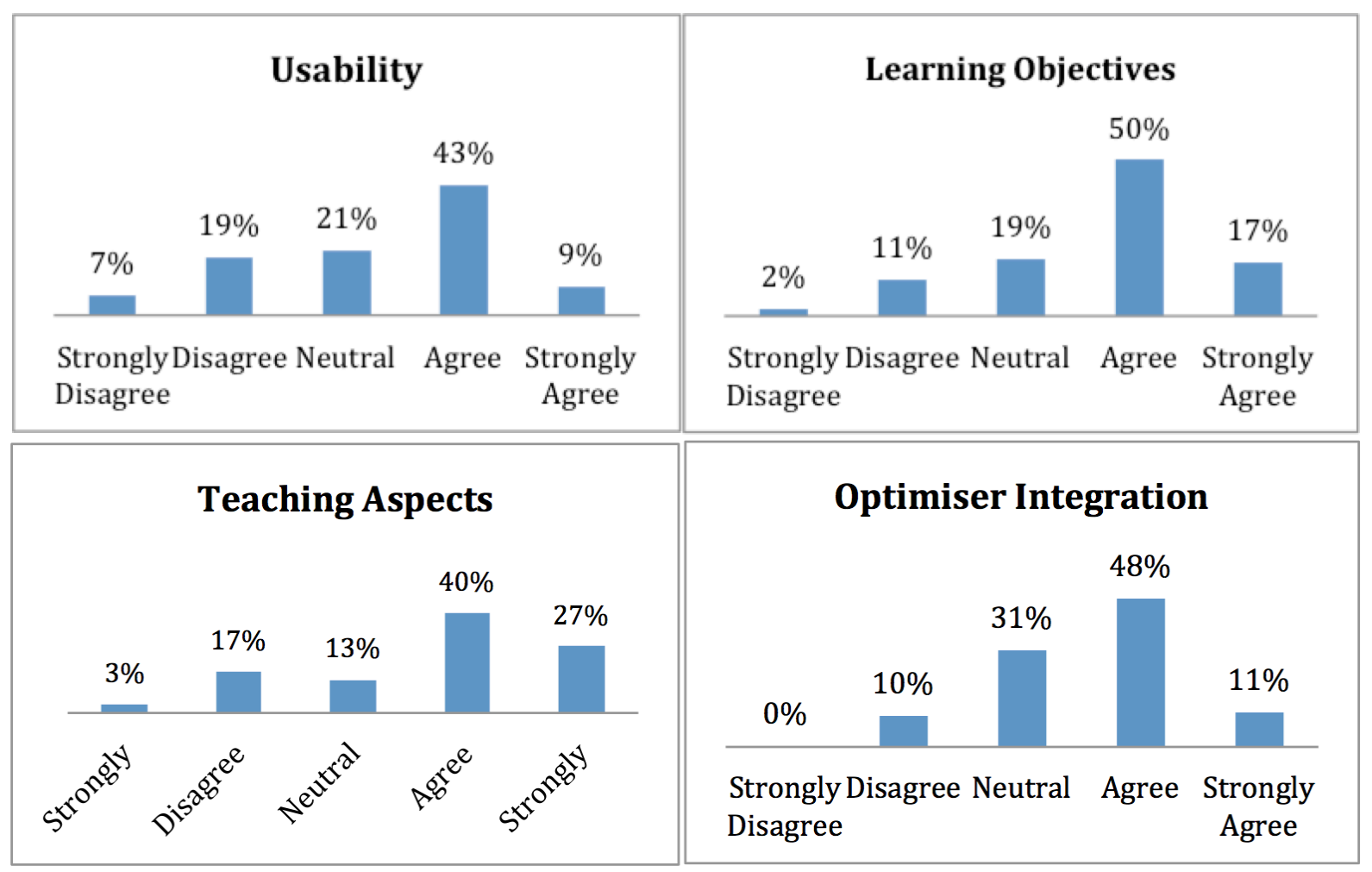

Fig. 8. Questionnaire Results.

\section{REFERENCES}

[1] Z. Abykanova, Bakytgul and Nugumanova, Samal and Yelezhanova, Shynar and Kabylkhamit, Zhanargul and Sabirova, "The Use of Interactive Learning Technology in Institutions of Higher Learning," Int. J. Environ. Sci. Educ., vol. 11, no. 18, 2016.

[2] F. Pasin and H. Giroux, "The impact of a simulation game on operations management education," Comput. Educ., vol. 57, no. 1, pp. 1240-1254, Aug. 2011.

[3] R. Van Eck, "Digital game-based learning: It' $s$ not just the digital natives who are restless ....," Educ. Rev., vol. 41, no. 2, pp. 1-16, 2006.

[4] T. Fleming, L. Bavin, and K. Stasiak, "Serious Games and Gamification for Mental Health: Current Status and Promising Directions," Front., 2017.

[5] N. Bu and B. C. Mitchell, "Student performance and perceptions in a web-based competitive computer simulation," Interdiscip. J. E-Learning Learn. Objects, vol. 5, 2009.

[6] M. Pivec and O. Dziabenko, "Game-based learning in universities and lifelong learning: UniGame: Social skills and knowledge training ' game concept 1," J. Univers. Comput. Sci., vol. 10, no. 1, pp. 14-26, 2004.

[7] E. M. C. Cruz, J. A. V. Cruz, J. G. R. Ruiz, and L. D. H. Hernández, "Video games in teachinglearning processes: A brief review," Int. J. Second. Educ., vol. 2, no. 6, pp. 102-105, 2015.

[8] R. Garris, R. Ahlers, and J. E. Driskell, "Games, motivation, and learning: A research and practice model,” Simul. Gaming, vol. 33, no. 4, pp. 441-467, Dec. 2002.

[9] A. Ranchhod, C. Gurău, E. Loukis, and R. Trivedi, "Evaluating the educational effectiveness of simulation games: A value generation model," Inf. Sci. (Ny)., vol. 264, pp. 75-90, Apr. 2014.

[10] R. Khalaila, "Simulation in nursing education: an evaluation of students' outcomes at their first clinical practice combined with simulations.," Nurse Educ. Today, vol. 34, no. 2, pp. 252-8, Feb. 2014.

[11] T. Koltai, S. Lozano, J. Uzonyi-Kecskés, and P. Moreno, "Evaluation of the results of a production simulation game using a dynamic DEA approach," Comput. Ind. Eng., vol. 105, pp. 
1-11, 2017.

[12] M. M. van Wyk, "The use of economics games as a participative teaching strategy to enhance student learning," J. Soc. Sci., vol. 35, no. 2, pp. 125-133, 2013.

[13] V. Wattanasoontorn, I. Boada, R. García, and M. Sbert, "Serious games for health," Entertain. Comput., vol. 4, no. 4, pp. 231-247, Dec. 2013.

[14] A. M. Ross, M. E. Fitzgerald, and D. H. Rhodes, "Game-based learning for systems engineering concepts," Procedia Comput. Sci., vol. 28, pp. 430-440, 2014.

[15] M. Gansterer, C. Almeder, and R. F. Hartl, "Simulation-based optimisation methods for setting production planning parameters," Int. J. Prod. Econ., vol. 151, no. 2014, pp. 206-213, 2014.

[16] R. Haijema and J. Bloemhof-ruwaard, "Hybrid simulation and optimisation approach to design and control fresh product networks," in Proceedings of the 2012 Winter Simulation Conference C. Laroque, J. Himmelspach, R. Pasupathy, O. Rose, and A.M. Uhrmacher, eds, 2012.

[17] A. A. Taleizadeh, S. T. A. Niaki, M.-B. Aryanezhad, and N. Shafii, "A hybrid method of fuzzy simulation and genetic algorithm to optimize constrained inventory control systems with stochastic replenishments and fuzzy demand," Inf. Sci. (Ny)., vol. 220, pp. 425-441, Jan. 2013.

[18] J. T. Lin and C.-M. Chen, "Simulation optimisation approach for hybrid flow shop scheduling problem in semiconductor back-end manufacturing," Simul. Model. Pract. Theory, vol. 51, no. 2015, pp. 100-114, 2015.

[19] D.-J. van der Zee, B. Holkenborg, and S. Robinson, "Conceptual modeling for simulation-based serious gaming," Decis. Support Syst., vol. 54, pp. 33-45, Mar. 2012.

[20] F. Costantino, G. Di Gravio, A. Shaban, and M. Tronci, "A simulation based game approach for teaching operations management topics," in Proceedings of the 2012 Winter Simulation Conference C. Laroque, J. Himmelspach, R. Pasupathy, O. Rose, and A.M. Uhrmacher, eds, 2012.

[21] R. J. Lancaster, "Serious game simulation as a teaching strategy in pharmacology," Clin. Simul. Nurs., vol. 10, no. 3, pp. e129-e137, Mar. 2014.

[22] K. Katsaliaki, N. Mustafee, and S. Kumar, "A game-based approach towards facilitating decision making for perishable products: An example of blood supply chain," Expert Syst. Appl., vol. 41, pp. 4043-4059, Jan. 2014.

[23] V. Aleven, E. Myers, M. Easterday, and A. Ogan, "Toward a framework for the analysis and design of educational games," in 2010 Third IEEE International Conference on Digital Game and Intelligent Toy Enhanced Learning, 2010, pp. 69-76.

[24] P. Dillenbourg and P. Jermann, "Technology for classroom orchestration," in New science of learning, New York: Springer Science, 2010, pp. 525-552.

[25] J. Schell, "The art of game design," vol. 2011, pp. 2008-2010, 2011. 